\title{
Effects of Vertebrobasilar Insufficiency on cVEMP Responses
}

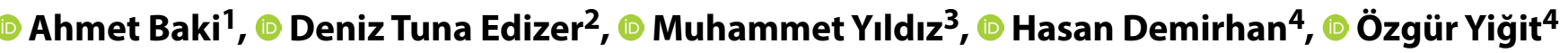 \\ ${ }^{1}$ Department of Otorhinolaryngology and Head Neck Surgery, Health Sciences University, Umraniye Training and Research Hospital, \\ Istanbul, Turkey \\ ${ }^{2}$ Department of Otorhinolaryngology Head and Neck Surgery, Health Sciences University, Izmir Bozyaka Training and Research \\ Hospital, Izmir, Turkey \\ ${ }^{3}$ Department of Otorhinolaryngolog, Rize State Hospital, Rize, Turkey \\ ${ }^{4}$ Department of Otorhinolaryngology Head and Neck Surgery, Health Sciences University Istanbul Training and Research Hospital, \\ Istanbul, Turkey
}

\begin{abstract}
Introduction: The aim of the present study was to evaluate cervical vestibular evoked myogenic potentials (cVEMPs) of patients with vertebrobasilar insufficiency (VBI).

Methods: Patients with vestibular complaints who were referred to the vestibular center were evaluated. All patients underwent a complete neurological examination, pure tone and speech audiometry, bithermal caloric test, Doppler ultrasonography of the carotid and vertebral arteries, and bilateral CVEMP recordings. Thirty patients with VBI and 30 healthy controls were included in the study. In the CVEMP test, latency and amplitude values of $95 \mathrm{~dB}$ were recorded.

Results: In the VBI group, the mean flow rate was $91.5 \pm 36.65 \mathrm{~mL} / \mathrm{min}$ at the side of higher flow, whereas it was $74.83 \pm 34.75$ $\mathrm{mL} / \mathrm{min}$ at the side of lower flow. In the control group, the mean flow rate was $151.5 \pm 26.62 \mathrm{~mL} / \mathrm{min}$ at the side of higher flow, whereas it was $140.5 \pm 33.69 \mathrm{~mL} / \mathrm{min}$ at the side of lower flow. There was a statistically significant difference between vertebral artery flow values between the VBI and control groups $(p<0.001)$. The right and left P13 $95 \mathrm{~dB}$ latency values in the $\mathrm{VBI}(-)$ group were $13.22 \pm 0.21 \mathrm{~ms}$ and $13.22 \pm 0.21 \mathrm{~ms}$, respectively, whereas those in the $\mathrm{VBI}(+)$ group were $16.15 \pm 0.11 \mathrm{~ms}$ and $16.23 \pm 0.14 \mathrm{~ms}$, respectively. The right and left N23 $95 \mathrm{~dB}$ latency values in the VBI (-) group were $23.09 \pm 0.14 \mathrm{~ms}$ and $25.39 \pm 0.88 \mathrm{~ms}$, respectively, whereas those in the $\mathrm{VBI}(+)$ group were $23.07 \pm 0.14 \mathrm{~ms}$ and $25.71 \pm 0.81 \mathrm{~ms}$, respectively. The right and left P13-N23 $95 \mathrm{~dB}$ amplitude values in the VBI (-) group were 41.46 $\pm 8.82 \mathrm{mV}$ and $41.41 \pm 6.81 \mathrm{mV}$, respectively, whereas those in the $\mathrm{VBI}(+)$ group were $24.81 \pm 3.36 \mathrm{mV}$ and $24.11 \pm 2.09 \mathrm{mV}$, respectively. There was a statistically significant difference between the VBI and control groups regarding latency and amplitude values at $95 \mathrm{~dB} \mathrm{nHL}$ stimulation $(p<0.001)$. Discussion and Conclusion: We believe that VBI is associated with abnormal cVEMP responses. Further studies with larger groups are needed to verify our findings.

Keywords: VEMP; vertebrobasilar insufficiency.
\end{abstract}

C ervical vestibular evoked myogenic potentials (cVEMPs) are electromyographic responses of the sternocleidomastoid muscle (SCM) that appear following stimulation of the saccule with electrical or acoustic stimuli ${ }^{[1]}$.

Since central vestibular pathways also participate within the vestibulocollic reflex arc, central nervous system dis- orders including multiple sclerosis, spinocerebellar degeneration, Parkinson's disease, and brainstem infarction may also change CVEMP results ${ }^{[2-4]}$.

Vertebrobasilar insufficiency (VBI) was demonstrated to play a role in the pathophysiology of labyrinthine dysfunction ${ }^{[5]}$. VBI leads to inadequate blood flow in the verte-

Correspondence (İletişim): Ahmet Baki, M.D. Saglik Bilimleri Universitesi, Umraniye Egitim ve Arastirma Hastanesi, Kulak Burun Bogaz ve Bas Boyun Cerrahisi Klinigi, Istanbul, Turkey

Phone (Telefon): +90 2166321818 E-mail (E-posta): dr.ahmet170@gmail.com

Submitted Date (Başvuru Tarihi): 03.03.2018 Accepted Date (Kabul Tarihi): 15.05.2018

Copyright 2019 Haydarpaşa Numune Medical Journal

OPEN ACCESS This is an open access article under the CC BY-NC license (http://creativecommons.org/licenses/by-nc/4.0/) 
bral system that may lead to transient ischemic attacks ${ }^{[6]}$. Although VBI has a diversity of clinical symptoms, vertigo is the most common symptom ${ }^{[7]}$. Electronystagmography abnormalities including positional, headshake, oculomotor, and caloric tests were demonstrated in patients with VBI ${ }^{[8]}$. On the other hand, CVEMP response changes were reported in brainstem cerebrovascular events ${ }^{[3,9,10]}$.

However, the effects of VBI on CVEMP results were not previously examined. The aim of the present study was to compare the CVEMP responses of patients with VBI with those of healthy individuals and to establish the effects of VBI on CVEMP.

\section{Materials and Methods}

A total of 130 patients with vestibular complaints who were referred to our clinic were investigated. The complete neurootological examination, cranial magnetic resonance imaging, caloric, vertebrobasilar Doppler ultrasonography, and CVEMP tests were performed for all patients. Thirty healthy subjects were classified as the control group. The study was approved by the local Ethics Committee (protocol no.: 465/11/04/2014). Informed consent was obtained from all patients.

Exclusion criteria included any neurological and otological disorders, hearing loss documented on pure tone audiometry, pathologic tympanogram, history of head and neck trauma, chronic systemic diseases, use of medications affecting the vestibular system, and the presence of any vestibular disorder other than VBI. Owing to the higher incidence of VEMP abnormalities in elderly people, subjects aged $>65$ years were excluded from the study.

\section{Doppler Sonography Measurements}

Doppler sonography evaluation of vertebrobasilar artery insufficiency was performed in a room temperature of $22{ }^{\circ} \mathrm{C}-24^{\circ} \mathrm{C}$ and after an adaptation period for at least 15 min rest in supine position. Right and left vertebral arteries (VAs) and internal carotid artery were examined with a 7.5-MHz linear array transducer of a Toshiba Nemio 20 system (Toshiba Nemio 20; Toshiba Medical Systems, Tokyo, Japan). The same operator performed scans. The patient's head was turned slightly to the opposite side each time. Flow volume measurements were recorded in the $\mathrm{C} 4$ and C5 segments of the VA and $1.5-2 \mathrm{~cm}$ from the carotid bifurcation. Cases with rates $<200 \mathrm{~mL} / \mathrm{min}$ total blood flow were diagnosed with VBI. Each side was examined separately. These patients' results were compared with healthy subjects without VBI and classified as the control group.

\section{cVEMP Recording}

The test was performed by a single researcher in a quiet room. Electrodes were placed on the forehead (ground electrode), on the central parts of each SCM (active electrodes), and on the sternal part of the SCM (reference electrode). The measurements were obtained while the participants were in the sitting position. Participants were asked to contralaterally turn their heads to the stimulated ear and to slightly tilt their heads forward to obtain sufficient muscle contraction. Monaural stimuli were given, respectively, to the right and left ears, and ipsilateral electromyographic activity of the SCM was recorded. During the test, the impedance of the electrodes was $<500 \Omega$. A tonal stimulus $(500 \mathrm{~Hz})$ was administered to both sides $(95 \mathrm{~dB})$ to test for CVEMPs in both ears. The CVEMP response (an initial positivity P13 followed by negativity N23) was recorded for each test. P13-N23 interpeak latencies and amplitudes were measured.

\section{Stimulus Design and Recording Set-up}

The cVEMP values were obtained from all participants using bilateral air conduction tone bursts with stimulus frequencies of $500 \mathrm{~Hz}$ to test the right and left ears. Calibrated ABR $3 \mathrm{~A}$ insert earphones (maximum intensity level $100 \mathrm{~dB} \mathrm{nHL}$ ) were used for stimulus transmission. The stimulus profile was adjusted to produce a $2 \mathrm{~ms}$ rise, a $2 \mathrm{~ms}$ plateau, and a $2 \mathrm{~ms}$ fall time with a repetition rate of $5.1 \mathrm{~Hz}$. A frequency of $500 \mathrm{~Hz}$ was presented $50-150$ times to obtain average responses. A VEMP evoked potential system (Eclipse EP 25; Interacoustics AS, Assens, Denmark) was used for CVEMP recordings. Disposable silver/silver chloride electrodes (Safe lead; Natus Neurology Incorporated, Middleton, WI, USA) with an impedance of $\leq 3 \mathrm{k} \Omega$ were used. An EMG feedback system (Interacoustics Eclipse; Interacoustics AS) was used for recording muscle responses between 50 and $200 \mu \mathrm{V}$. EMG was amplified ( $60 \mathrm{~dB})$ and bandpass filtered (10-750 $\mathrm{Hz}$ ). Muscle responses were recorded from $10 \mathrm{~ms}$ before the stimulus onset to $60 \mathrm{~ms}$ afterward. To improve reliability and reduce interpatient variability, the test was performed twice, and cVEMP amplitudes were normalized by dividing raw amplitudes by the background EMG activity.

\section{Statistical Analysis}

When evaluating the findings obtained in the present study, IBM SPSS Statistics 22 for statistical analysis (SPSS IBM, Turkey) programs were used. Shapiro-Wilk test was used to evaluate the normal distribution of the parameters. Student's t-test was used to compare descriptive statistical methods, as well as the two-group comparison of 
parameters with normal distribution in the comparison of quantitative data. Data were expressed as mean, standard deviation, and frequency. Mann-Whitney $U$ test was used to compare the two groups of parameters without normal distribution. Paired sample t-test was used for the right ear and left ear comparisons of quantitative data showing normal distribution. Wilcoxon signed-rank test was used to assess the without normal distribution of the right ear and left ear comparisons. Continuity (Yates) correction was used to compare qualitative data. A p-value $<0.05$ was considered statistically significant.

\section{Results}

There were 30 ( 15 male and 15 female) patients with VBI and 30 (15 male and 15 female) controls. The mean ages were $49 \pm 4.27$ years for the patient group and $44.7 \pm 2.44$ years for the control group. No statistical significance was found in age and gender distribution between the groups $(p>0.05)$.
The VA flow rate was higher at the right side in 16 patients, whereas it was higher at the left side in 14 patients with $\mathrm{VBI}$. Mean flow rate at the side of higher flow was $91.5 \pm 36.65 \mathrm{~mL} / \mathrm{min}$, whereas that at the side of lower flow was $74.83 \pm 34.75 \mathrm{~mL} / \mathrm{min}$ (Table 1).

In the control group, the higher flow rate was observed at the right side in 17 subjects, whereas it was observed at the left side in 13 subjects. Mean flow rate was $151.5 \pm 26.62 \mathrm{~mL} / \mathrm{min}$ on the side of higher flow rate, whereas it was $140.5 \pm 33.69$ $\mathrm{mL} / \mathrm{min}$ on the side of lower flow rate (Table 1 ).

There was a statistically significant difference between high flow value and low flow value between the VBI (+) group and VBI $(-)$ group $(p<0.001)$ (Table 1). Patients with $\mathrm{VBI}$ were compared with controls; there was a statistically significant prolongation of $\mathrm{P} 13$ and $\mathrm{N} 23$ latency values $(p<0.001)$ (Table 2 ). When patients with VBI were compared with controls, there was a statistically significant decrease in P13-N23 amplitude values $(p<0.001)$ (Table 2).

Table 1. Vertebrobasilar artery flow averages and p-values in VBI (+) and VBI (-) groups

\begin{tabular}{lcr}
\hline Vertebrobasilar arterial flow (mL/min) & $\begin{array}{c}\text { VBI (+) } \\
\text { Average } \pm \text { SD }\end{array}$ & $\begin{array}{c}\text { VBI (-) } \\
\text { Average } \pm \text { SD }\end{array}$ \\
\hline High vertebrobasilar arterial flow & $91.5 \pm 36.65$ & $151.5 \pm 26.62$ \\
Low vertebrobasilar arterial flow & $74.83 \pm 34.75$ & $140.5 \pm 33.69$ \\
\hline
\end{tabular}

Student t-Test * $\mathrm{p}<0.05 ; \mathrm{VBI}(+)$ : Group of patients with vertebrobasilar insufficiency; VBI (-): Healthy control group without vertebrobasilar insufficiency; SD: Standard Deviation; ( $\mathrm{ml} / \mathrm{min})$ : (millilitre/minute).

Table 2. The average P13-N23 latency values, average amplitude values and p-values in VBI (+) and VBI (-) groups

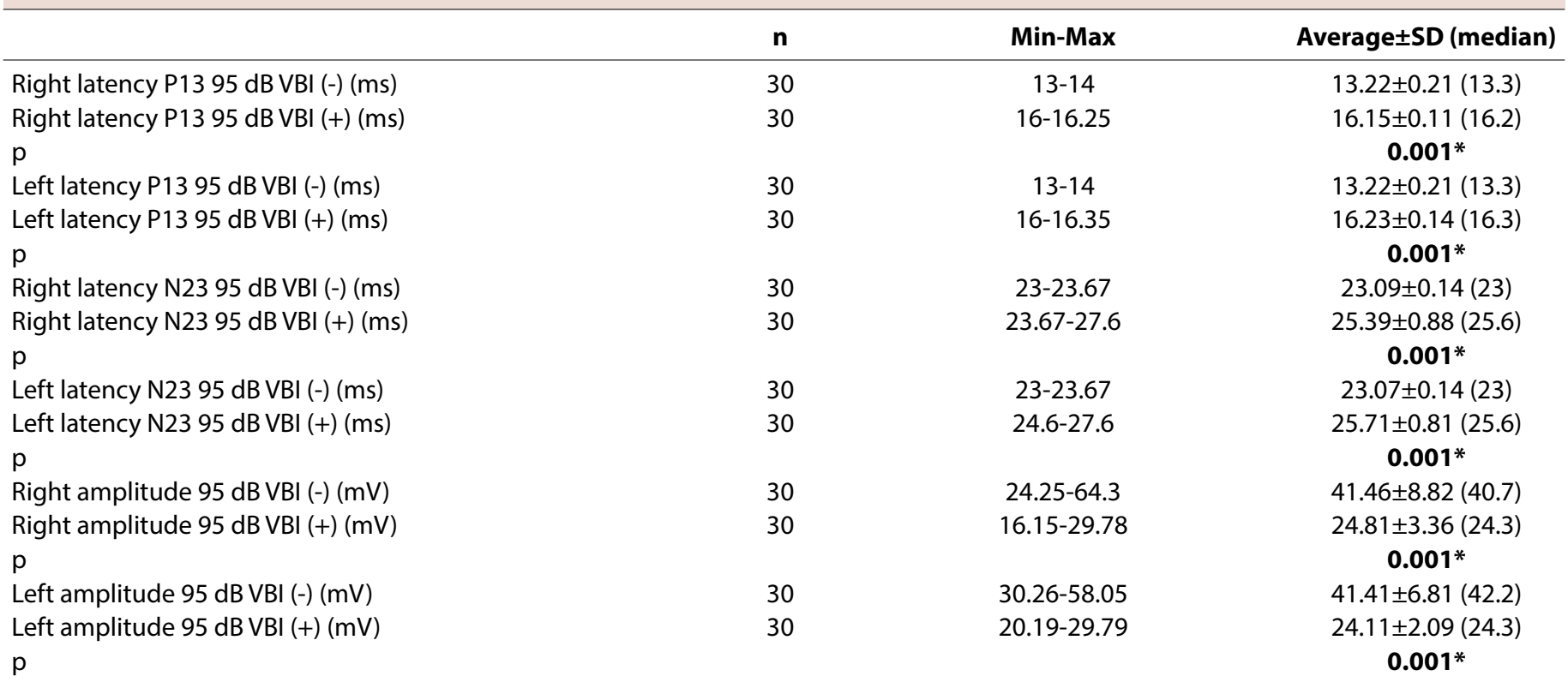

Wilcoxon Sign Test; ${ }^{*} p<0.05 ; \mathrm{VBI}(+)$ : Group of patients with vertebrobasilar insufficiency; VBI (-): Healthy control group without vertebrobasilar insufficiency; P13: The first positive peak wave; N23: The first negative peak wave; dB: decibel; SD: Standard Deviation; ms: milisecond; mV: microvolt. 


\section{Discussion}

Vertigo can cause many adverse effects on the social, emotional, and job-related aspects of life. Among the causes of central vertigo, vascular causes are the most common. Diseases that may lead to central vertigo include posterior inferior cerebellar artery syndrome, anterior inferior cerebellar artery syndrome, superior cerebellar artery syndrome, insular infarct, cerebellar and brainstem hemorrhages, and transient ischemic attacks in the vertebrobasilar system ${ }^{[10]}$.

The vertebrobasilar artery system accounts for $20 \%$ of cerebral perfusion and provides vascular supply to both central and peripheral vestibular organs ${ }^{[11]}$. Disturbed circulation of the vertebrobasilar system, known as VBI, often results in vertigo, which may be the early symptom of VBI before later symptoms of stroke that occur in $28 \%$ of VBI cases ${ }^{[12]}$. It often results in embolic events and less frequently as a result of reduced flow vertebral and basilar arteries or branches [13]. The classic presentation of VBI includes episodic vertigo with head motion, imbalance, dysarthria, hemiparesis, ataxia and drop attacks, and sudden sensorineural hearing loss ${ }^{[14,15]}$. Although audiovestibular symptoms can be the first and sole clinical signs of VBI, it can be easily misdiagnosed as the peripheral labyrinthine disorder and attributed to $\mathrm{VBI}$ vertigo ${ }^{[16]}$.

Many different non-invasive imaging techniques can quantitatively assess the blood flow volume, but only sonography and magnetic resonance imaging allow phase contrast flow quantification to assess individual vessels $[17,18]$. Doppler examination of extracranial arteries has become a common and reliable tool in evaluating patients with VBI suspicion ${ }^{[19,20]}$. American Academy of Neurology Doppler ultrasound is a diagnostic tool for determining vascular pathologies because of its high sensitivity and specificity [21]. In our study, we applied the Doppler ultrasound test for patients with vertigo, and we performed the CVEMP test for patients with VBI.

The cVEMP test evaluates the saccule-colic reflex way to the lower brainstem ${ }^{[22]}$. It is generated using a disynaptic pathway and beginning in the saccule after proceeding along vestibular afferent fibers to the vestibular nuclei and then through quickly conducting projections that synapse with sternomastoid nuclei ${ }^{[23]}$. The test can be achieved with tone burst and electrical and vibrational stimuli, but mainly with click stimuli ${ }^{24]}$. In our study, we have used the click stimulus, and the best responses in the frequency range of $200-1000 \mathrm{~Hz}$ are obtained with click stimuli ${ }^{[25]}$. The test is performed at a range of $85-100 \mathrm{~dB}$, and the best response is $95 \mathrm{~dB} \mathrm{nHL}{ }^{[25]}$. In the test, the saccule functions are best evaluated at $500 \mathrm{~Hz}$ frequency ${ }^{[26]}$. In our study, we evaluated cVEMP responses at $500 \mathrm{~Hz}$ frequency and $95 \mathrm{~dB}$ $\mathrm{nHL}$ stimulation in patients with VBI and controls.

Afferent fibers from the utriculi, saccule, and semicircular channels at the ear reach the brainstem vestibular nucleus in the central nervous system [27]. The labyrinth is more susceptible to atherosclerotic vascular diseases due to the small size of the vasculature ${ }^{[28,29]}$. Whether the labyrinthine system is affected by vascular pathologies can be demonstrated by the CVEMP test, a non-invasive practical test ${ }^{[30]}$. The $C V E M P$ test can be used to diagnose various central and peripheral vestibular diseases ${ }^{[30,31]}$. Delay in latency in VEMP responses, fall in amplitudes, and loss of amplitude are considered pathologic ${ }^{[31]}$. Abnormal VEMP responses are obtained in the brainstem, retrolabyrinthine, or labyrinthine pathologies ${ }^{[4,32]}$. Chen et al. ${ }^{[33]}$ detected patients with cerebrovascular disease based on VEMP responses. A total of 3 out of 14 had normal latencies, another 3 out of 14 had prolonged latencies, and 8 out of 14 had no response. Delayed vestibular evoked myogenic potentials (prolonged latencies) indicate brainstem lesion, especially in the vestibulospinal tract. We found especially latency prolongation in the $\mathrm{VBI}$ group appropriate with the literature.

Chuang et al. ${ }^{[30]}$ compared 26 patients diagnosed with congenital arterial hypoplasia and 26 healthy patients regarding VEMP responses. Overall, $88.47 \%$ of patients with VA hypoplasia (VAH) were found to have unilateral or bilateral delayed VEMP responses. All 18 patients with VAH in the right ear showed prolonged latencies on the ipsilateral side, which may have been due to insufficient perfusion of the vestibular system. In demyelination of the vestibulospinal tract, the mean latencies of P13 and N23 are prolonged. Ischemic axonal damage results in segmental demyelination. They asserted that a delayed response or absence of ipsilateral VEMP could be attributed to "hypoperfusion" of the VAH. VBI and VAH selectively might damage the sacculocollic/ vestibulospinal pathway because of its high energy requirement and lack of collateral circulation [34].

In the VBI group, we found latency prolongation and a decrease in amplitude values according to controls. VBI may lead to repetitive hypoperfusion injury to corresponding peripheral and central vestibular systems that may cause abnormal cVEMP responses. A large-scale study is necessary to establish the relationship between VBI and CVEMP responses. Furthermore, other vestibular tests are needed in addition to the CVEMP test that will reveal the clinical results of the effects of VBI on the vestibular system. 


\section{Conclusions}

We believe that is associated with abnormal cVEMP is a real entity that deserves more attention. cVEMP may be an integral part of the diagnosis and differential diagnosis of vertigo caused by VBI.

Ethics Committee Approval: The study was approved by the local Ethics Committee (Protocol no.: 465/11/04/2014).

Peer-review: Externally peer-reviewed.

Authorship Contributions: Concept: A.B., M.Y.; Design: A.B., M.Y.; Data Collection or Processing: A.B., H.D.; Analysis or Interpretation: A.B., D.T.E.; Literature Search: A.B., Ö.Y.; Writing: A.B., M.Y.

Conflict of Interest: None declared.

Financial Disclosure: The authors declared that this study received no financial support.

\section{References}

1. Murofushi T, Kaga K. Vestibular evoked myogenic potential: its basics and clinical applications. Tokyo: Springer; 2009. [CrossRef]

2. Venhovens J, Meulstee J, Verhagen WIM. Vestibular evoked myogenic potentials (VEMPs) in central neurological disoders. Clin Neurophysiol 2016;127:40-49. [CrossRef]

3. Murofushi T. Clinical application of vestibular evoked myogenic potential (VEMP). Auris Nasus Larynx 2016;43:367-76.

4. Murofushi T, Shimizu K, Takegoshi H, Cheng PW. Diagnostic value of prolonged latencies in the vestibular evoked myogenic potential. Arch Otolaryngol Head Neck Surg 2001;127:1069-72. [CrossRef]

5. Savitz SI, Caplan LR. Vertebrobasilar disease. N Engl J Med 2005;352:2618-26. [CrossRef]

6. Yang FC, Chen SY, Yin JH, Lin CC, Sung YF, Chou CH, et al. The association between vertebrobasilar insufficiency and the risk of dementia: a nationwide register-based retrospective cohort study in Taiwan. BMJ Open 2017;7:e017001. [CrossRef]

7. Yamasoba T, Kikuchi S, Higo R. Deafness associated with vertebrobasilar insufficiency. J Neurol Sci 2001;187:69-75. [CrossRef]

8. Mohamed ES, Kaf WA, Rageh TA, Kamel NF, Elattar AM. Evaluation of patients with vertigo of vertebrobasilar insufficiency origin using auditory brainstem response, electronystagmography, and transcranial Doppler. Int J Audiol 2012;51:379-88.

9. Skorić MK, Adamec I, Pavičić T, Pavlović I, Ruška B, Crnošija L, et al. Vestibular evoked myogenic potentials and video head impulse test in patients with vertigo, dizziness and imbalance. J Clin Neurosci 2017;39:216-220. [CrossRef]

10. Karatas M. Central vertigo and dizziness: epidemiology, differential diagnosis, and common causes. Neurologist 2008;14:355-64. [CrossRef]

11. Lee $H, A$ hn $B H$, Baloh RW. Sudden deafness with vertigo as a sole manifestation of anterior inferior cerebellar artery infarction. J Neurol Sci 2004;222:105-7. [CrossRef]

12. Grad A, Baloh RW. Vertigo of vascular origin. Clinical and electronystagmographic features in 84 cases. Arch Neurol 1989;46:281-4. [CrossRef]
13. Seidel E, Eicke BM, Tettenborn B, Krummenauer F. Reference values for vertebral artery flow volume by duplex sonography in young and elderly adults. Stroke 1999;30:2692-6. [CrossRef]

14. Hülse $M$, Hölzl $M$. Vestibulospinal reactions in cervicogenic disequilibrium. Cervicogenic imbalance. [Article in German]. HNO 2000;48:295-301. [CrossRef]

15. Ballesteros F, Alobid I, Tassies D, Reverter JC, Scharf RE, Guilemany JM, et al. Is there an overlap between sudden neurosensorial hearing loss and cardiovascular risk factors? Audiol Neurootol 2009;14:139-45. [CrossRef]

16. Petrova D, Hannig A. Electronystagmographic and caloric investigation data about vascular-vestibular dysfunction among patients with vertebrobasilar insufficiency. Int Tinnitus J 2003;9:48-51.

17. Cakmakci E, Ozal ST, Ogutcu EK, Aydin A, Tunc S, Kaygusuz U, et al. Are there any novel radiological diagnostic clues in magnetic resonance imaging for vertebrobasilar insufficiency? Quant Imaging Med Surg 2015;5:846-52.

18. Alpaidze M, Janelidze M. Application of sonography for evaluation of posterior circulation disorders. Georgian Med News 2014;228:20-8.

19. Zivadinovic B, Stamenović J, Ljubisavljevic S. The comparative analyses of the auditory evoked potentials and color Doppler sonography findings in patients diagnosed with vertebrobasilar insufficiency. Neurol Res 2014;36:939-44. [CrossRef]

20. Grgić V. Vertebrobasilar insufficiency and obstructive sleep apnea. [Article in Croatian]. Lijec Vjesn 2011;133:50-5.

21. Sloan MA, Alexandrov AV, Tegeler $\mathrm{CH}$, Spencer MP, Caplan LR, Feldmann E, et al; Therapeutics and Technology Assessment Subcommittee of the American Academy of Neurology. Assessment: transcranial Doppler ultrasonography: report of the Therapeutics and Technology Assessment Subcommittee of the American Academy of Neurology. Neurology 2004;62:1468-81. [CrossRef]

22. Sürmeli $M$, Sürmeli R, Deveci İ, Önder $S$, Yalçın AD, Oysu Ç. Correlation between CVEMP and ABR for the Evaluation of Vestibular Migraine. J Int Adv Otol 2016;12:326-31. [CrossRef]

23. Kim CH, Jang MU, Choi HC, Sohn JH. Subclinical vestibular dysfunction in migraine patients: a preliminary study of ocular and rectified cervical vestibular evoked myogenic potentials. J Headache Pain 2015;16:93. [CrossRef]

24. Rosengren SM, McAngus Todd NP, Colebatch JG. Vestibularevoked extraocular potentials produced by stimulation with bone-conducted sound. Clin Neurophysiol 2005;116:1938-48.

25. Murofushi T, Matsuzaki M, Wu CH. Short tone burst-evoked myogenic potentials on the sternocleidomastoid muscle: are these potentials also of vestibular origin? Arch Otolaryngol Head Neck Surg 1999;125:660-4. [CrossRef]

26. Agrawal Y, Bremova T, Kremmyda O, Strupp M, MacNeilage PR. Clinical testing of otolith function: perceptual thresholds and myogenic potentials. J Assoc Res Otolaryngol 2013;14:905-15.

27. Jamon $M$. The development of vestibular system and related functions in mammals: impact of gravity. Front Integr Neurosci 2014;8:11. [CrossRef] 
28. Gomez CR, Cruz-Flores S, Malkoff MD, Sauer CM, Burch CM. Isolated vertigo as a manifestation of vertebrobasilar ischemia. Neurology 1996;47:94-7. [CrossRef]

29. Castro Junior NP, Almeida $\mathrm{Cl}$, Campos CA. Sudden sensorineural hearing loss and vertigo associated with arterial occlusive disease: three case reports and literature review. Sao Paulo Med J 2007;125:191-5. [CrossRef]

30. Chuang YM, Chen CC, Lin CP. Vertebral artery hypoplasia may contribute to abnormal vestibular evoked myogenic potentials. Acta Neurol Taiwan 2009;18:113-7.

31. Takeichi N, Sakamoto T, Fukuda S, Inuyama Y. Vestibular evoked myogenic potential (VEMP) in patients with acoustic neuromas. Auris Nasus Larynx 2001;28 Suppl:S39-41. [CrossRef]

32. Heide G, Luft B, Franke J, Schmidt P, Witte OW, Axer H. Brainstem representation of vestibular evoked myogenic potentials. Clin Neurophysiol 2010;121:1102-8. [CrossRef]

33. Chen $\mathrm{CH}$, Young $\mathrm{YH}$. Vestibular evoked myogenic potentials in brainstem stroke. Laryngoscope 2003;113:990-3. [CrossRef]

34. Dyck PJ, Norell JE, Dyck PJ. Microvasculitis and ischemia in diabetic lumbosacral radiculoplexus neuropathy. Neurology 1999;53:2113-21. [CrossRef] 